\title{
Bir Üniversite Hastanesinde Çalışan Hemşirelerin Bilinçli Farkındalık Düzeylerinin Belirlenmesi
}

\author{
Elif AŞIK ${ }^{1}$, Sevil ALBAYRAK [0] $^{2}$
}

\section{ÖZ}

Amaç: Bilinçli farkındalık; açık bir merak ve kabul ile içinde bulunulan anın deneyimine dikkatlice odaklanmak olup, hemşirelerin hemşirelik bakımı vermelerini etkileyen konulardan birisidir. $\mathrm{Bu}$ araştırma, hemşirelerin bilinçli farkındalık düzeylerini belirlemek amacıyla yapıldı.

Gereç ve Yöntemler: Tanımlayıcı tipte olan araştırmanın evrenini Kırıkkale Üniversitesi Tıp Fakültesi Hastanesinde çalışan 207 hemşire oluşturdu. Araştırma 158 hemşire ile Şubat-Mart 2020 tarihleri arasında tamamlandı. Veriler, Kişisel Bilgi Formu ve Bilinçli Farkındalık Ölçeği ile öz bildirim yöntemiyle elde edildi. Bu araştırma için kurum ve ölçek kullanım izni, etik kurul onayı ve hemşirelerden sözlü onam alındı. Verilerin analizinde; iki ortalama arasındaki farkın önemlilik testi, tek yönlü varyans analizi, Kruskal-Wallis testleri kullanıldı.

Bulgular: Araştırmaya katılan hemşirelerin $(\mathrm{n}=158)$ yaş ortalaması $32,38 \pm 7,36$ 'dır. Hemşirelerin \%77,2'si kadın, \%72,2'si fakültte/yüksekokul mezunu, \%63,3'ü evlidir. Hemşirelerin yarısı (\%50,6's1) dahili kliniklerde çalışmakta olup \%74,7'si nöbetli çalışmaktadır. Hemşirelerin Bilinçli Farkındalık Ölçeği puan ortalaması 63,98ะ12,41'dir. Hemşirelerin cinsiyetleri ve nöbet tutma durumları ile Bilinçli Farkındalık Ölçeği puan ortalamaları karşılaştıııldığında çıkan fark istatistiksel olarak anlamlıdır $(\mathrm{p}<0,05)$.

Sonuç: Bu araştırmaya katılan hemşirelerin bilinçli farkındalık düzeyleri orta düzeyde bulundu. Hemşirelerin bilinçli farkındalık düzeylerinin, farkındalık eğitimi ve farkındalı̆̆ arttırmaya yönelik egzersizler ile yükseltilmesi önerilir. Araştırmada, hemşirelerin cinsiyet ve çalışma şekline göre bilinçli farkındalık puanlarında fark olduğu saptandı. $\mathrm{Bu}$ bulgu, daha geniş kapsamlı araştırmalarla yordanmalıdır.

Anahtar Kelimeler: Farkındalık; hemşireler; psikoloji.

\section{Determining Mindfulness Levels of the Nurses Working in a University Hospital}

\begin{abstract}
Aim: Mindfulness which focusing on the experience of the present moment with an open curiosity and acceptance is one of the issues that affect the nursing care of nurses. This research was carried out to determining mindfulness levels of the nurses.

Material and Methods: In this descriptive research, 207 nurses working at Kırıkale University medical Faculty Hospital constituted the population. The research completed with 158 nurses during February to March in 2020. The data were obtained with the Personal Information Form and the Conscious Awareness Scale by the self-report method. For this research, institution and scale usage permission, ethics committee approval, and verbal consent from nurses were obtained. Personal Information Form and Mindful Attention Awareness Scale were applied to the nurses who agreed to participate in the research $(n=158)$. The significance test of the difference between the two means, one-way analysis of variance and Kruskal-Wallis tests were used in the analysis of the data.

Results: The average age of the nurses $(n=158)$ participating in the study is $32.38 \pm 7.36 .77 .2 \%$ of the nurses are women, $72.2 \%$ are graduates of faculties/junior college, $63.3 \%$ are married, $50.6 \%$ of the nurses work in internal clinics and 74.7\% nurses work with shift working status. The mean score of Mindful Attention Awareness Scale of the nurses participating in the research was $63.98 \pm 12.41$. There was a statistically significant difference between average
\end{abstract}

1 Kırıkkale Üniversitesi, Sağlık Bilimleri Fakültesi, Hemşirelik Bölümü, Ruh Sağlığı ve Hastalıkları Hemşireliği Anabilim Dalı, Kırıkkale, Türkiye 2 Kırıkkale Üniversitesi, Sağlık Bilimleri Fakültesi, Hemşirelik Bölümü, Halk Sağlığı Hemşireliği Anabilim Dalı, Kırıkkale, Türkiye 
mindfulness scores of nurses when compared to their gender and shift working status $(\mathrm{p}<0.05)$.

Conclusion: Mindfulness level of the nurses participating in this research are at a medium level. It is recommended to increase the mindfulness level of nurses with mindfulness training and exercises aimed at increasing mindfulness. In this research, it was found that there was a difference in mindfulness scores of nurses according to their gender and shift working status. This finding has been predicted by more extensive research.

Keywords: Awareness; nurses; psychology.

\section{GíRiș}

Bilinçli farkındalık (Mindfulness) kökeni doğu geleneklerine dayanan bir dikkat yönlendirme şeklidir (1). Bishop ve ark. (2) bilinçli farkındalığı; açık bir merak ve kabul ile içinde bulunulan anın deneyimine dikkatlice odaklanmak olarak tanımlar. Bilinçli farkındalık, içinde bulunulan anda gerçekleşenlere dikkat etmek, bu dikkatin niteliğini fark etmek ve tüm bu fark edilenlere, yargılamadan kabul edici bir şekilde odaklanmayı içerir (3-5). Bilinçli farkındalık sadece içinde bulunulan anı fark etmek ve şimdiki anda yaşamak anlamına gelmez. Şimdiki an içinde olanları fark etmeyi ve tüm bu fark edilenleri karşılama biçimini içerir. $\mathrm{Bu}$ nedenle, bilinçli farkındalığa, algılama ve algılananı kabul etmenin karışımından oluşan bir yaklaşım denilebilir. Sadece algılamak, dikkatten ibarettir. Bilinçli farkındalık ise mevcut anı, hem bilinçli bir akıl hem de açık, sevgi ve şefkat dolu bir kalple algılamaktır (3).

Birey karşısındakinin tepkilerine dikkat etmeden, dürtüsel ve otomatik davranışlar sergilerse bilinçli farkındalık tehlikeye girebilir (6). Umursamazlık ise bilinçli farkındalığın karşıtı ve bilinçli farkındalığın göreceli yokluğudur (5).

Bilinçli farkındalığı yüksek olanların acı veren sorunlar yaşadıklarında, bu sorunlara yoğun bir şekilde odaklanmak yerine, sorunların farkına vardıkları belirtilmektedir. $\mathrm{Bu}$ farkındalık, olumsuz yargılamayı ortadan kaldırır, öz eleştiriyi hafifletir ve kendini anlamayı sağlar. Öz şefkat dolayısıyla öz anlayışın arttığı araştırmalarda gösterilmektedir $(7,8)$. Bilinçli farkındalığ arttırmak için egzersizler ve düzenli meditasyon yapan bireylerin; kayg1, stres, depresyon düzeyleri düştüğü, tükenmişlik ile baş etmeleri geliştiği ve mutluluk düzeylerinin daha yüksek olduğu literatürde belirtilmektedir $(9,10)$.

Hemşireler, bakım verirken bireyler ve çevre ile temasa girerler. $\mathrm{Bu}$ nedenle hemşirelik mesleği bilinçli farkındalığın en üst seviyede olması gereken meslekler grubundadır. Hemşireler hem hastalarını gözlemleyerek, hem de hasta ve hasta yakınlarıyla görüşerek, onların sorunlarını, gereksinimlerini, yeterliliklerini ve çevreleriyle uyum düzeylerini değerlendirerek bakım verirler. Hasta ile etkileşiminde tedavi edici unsur olabilmek için, bir hemşirenin öncelikle kendini tanıması ve çevresindekiler üzerinde bırakmış olduğu etkileri anlaması gerekmektedir. Çalışmalar, bilinçli farkındalığın mental sağlığı geliştirdiğini ortaya koymaktadır. Bilinçli farkındalığı arttırmaya yönelik uygulamalarla, hemşirelerde (13) ve hemşirelik öğrencilerinde (14) stres seviyelerinin düştüğünü gösteren çalışmalar mevcuttur (15). Sanko ve ark.'nın (11) hemşire ve hemşirelik öğrencilerinde, bilinçli farkındalık eğitim programının etkilerini inceledikleri çalışmalarında; katılımcılarda bilinçli farkındalık düzeylerinin artmasıyla birlikte, uyku, stres, konsantrasyon ve dikkat alanlarında iyileşmeler tespit edilmiştir. Horner ve ark. (12) ise bir klinikte çalışan tüm hemşirelere 10 haftalık bilinçli farkındalık eğitimi vermiş ve hemşirelerin bilinçli farkındalık puanlarının artmasıyla birlikte, tükenmişlik ve stres düzeylerinde iyileşme olduğunu belirlemişılerdir. Aynı çalışmada; hastaların memnuniyetleri de artmış ve hastalar hemşireler ile daha iyi iletişim kurduklarını ifade etmişlerdir. Bilinçli farkındalığın, hemşirelerin kendini tanıması ve etrafında yaşanan olayların bırakmış olduğu etkilerin farkında olması için gerekli bir uygulama olduğu görülmektedir. Literatür incelendiğinde, ülkemizdeki hemşirelerin bilinçli farkındalık düzeylerine yönelik çalışmaların çok az olduğu görülmüştür. $\mathrm{Bu}$ bağlamda araştırmanın amacı, ülkemizde bir üniversite hastanesinde çalışan hemşirelerin bilinçli farkındalık düzeylerinin belirlenmesidir. $\mathrm{Bu}$ amaçla; hemşirelerin, bazı demografik ve mesleki özelliklerinin tanımlanması ve bu özelliklere göre bilinçli farkındalık düzeylerinin belirlenmesi hedeflenmiştir.

\section{GEREÇ VE YÖNTEMLER Araştırmanın Tipi ve Örneklem}

$\mathrm{Bu}$ araştırma, Kırıkkale Üniversitesi Tıp Fakültesi Hastanesinde çalışan hemşirelerin bilinçli farkındalık düzeylerini belirlemek amacıyla tanımlayıcı araştırma tipinde yapıldı. Araştırmanın evrenini Kırıkkale Üniversitesi Tıp Fakültesi Hastanesinde çalışan 207 hemşire oluşturdu. Örneklem seçimine gidilmeyip, araştırmaya katılmayı kabul eden 158 (evrenin \%76,3’ü) hemşireye 01 Şubat- 10 Mart 2020 tarihleri arasında veri toplama araçları uygulandı. G-Power 3.1.9.6 programında post hoc $\mathrm{t}$ testi yapıldı ve 0,66 etki büyüklüğünde 1,0 bulundu, tam güçle sonucun elde edildiğine karar verildi.

\section{Veri Toplama Araçları}

Araştırmanın verilerini toplamak için araştırmacılar tarafından literatüre dayalı $(16,17)$ hazırlanan "Kişisel Bilgi Formu" ve Brown ve Ryan (5) tarafindan geliştirilip, Türkçe'ye uyarlaması Özyeşil ve ark. (18) tarafından yapılan "Bilinçli Farkındalık Ölçeği (BİÖ)" kullanıldı. Veri toplama araçları katılımcılara dağıtılıp, öz bildirim yoluyla soruları cevaplamaları sağlandı. Katılımcıların veri toplama araçlarını doldurması yaklaşık 20 dakika sürdü.

Kişisel Bilgi Formu; katılımcıların yaş, cinsiyet, eğitim durumu, medeni durumu, çalışmakta olduğu birim, çalıştığı birimde nöbet tutma durumu, çalışma yılı ve ekonomik durumunu nasıl algıladığına ilişkin sorulardan oluşmuştur.

BİFÖ günlük hayattaki anlık deneyimleri ve bunlar karşısındaki dikkati ölçen 15 maddeden oluşan bir kendini değerlendirme ölçeğidir. Tek faktörlü olup tek toplam puan verir. Ölçekten düşük puan alındığında (en düşük 15) bilinçli farkındalığın düşük olduğu, yüksek puan alındığında (en yüksek 90) bilinçli farkındalığın yüksek olduğu anlamına gelir. Bazı araştırmalarda ölçek ağırlıklarına göre hesaplanmış ve puanı en düşük 1 en yüksek 6 kabul edilmiştir $(12,13,19)$. Bu araştırmada; her iki hesaplama yöntemi de kullanılarak, sonuçları gösterildi. BİFÖ altı dereceden (hemen hemen her zaman, 
çoğu zaman, bazen, nadiren, oldukça seyrek, hemen hemen hiçbir zaman) oluşan likert tipi ölçektir. BİFÖ’nün iç tutarlılık katsayısı 0,82 , test-tekrar güvenirliği ise 0,81 olarak bulunmuştur. $\mathrm{Bu}$ araştırmada, bilinçli farkındalık ölçeğinin güvenirlik katsayısı 0,87 olarak saptandı.

\section{İstatistiksel Analiz}

Araştırmadan elde edilen verilerin analizi bilgisayarda, SPSS 20,0 istatistik programında gerçekleştirildi. Araştırma verilerinin analizinde tanımlayıcı istatistikler (sayı, yüzde, ortalama, standart sapma, ortanca ve minimum-maksimum) kullanıldı. Değişkenlerin normal dağılıma uygunluk testleri (Kolmogorov-Smirnov testi, Shapiro-Wilk testi) yapıld1. Bu testler sonucunda, normal dağıldığı görülen cinsiyet, medeni durum, çalışma yılı, nöbet tutma durumu bağımsız değişkenlerinin BİFÖ toplam puanı ile karşılaştırılmasında iki ortalama arasındaki farkın önemlilik testi (t testi) ve tek yönlü varyans analizi (F) kullanıldı. Normal dağılmayan, çalışılan birim, eğitim durumu ve ekonomik durum algısı için Kruskal-Wallis (KW) testi kullanıldı. İstatistiksel anlamlılık değeri $\mathrm{p}<0,05$ olarak belirlendi.

\section{Araștırmanın Etik Yönü}

Araştırmanın planlanma aşamasında Doç. Dr. Zümra Atalay'dan ölçek izni alındı. Kırıkkale Üniversitesi Girişimsel Olmayan Araştırmalar İçin Etik Kuruldan onay (Karar No: 2020.01.20), Kırıkkale Üniversitesi Tıp Fakültesi Dekanlığından yazılı izin ve katılımcılardan onam alındı. Araştırma ve makale yazım sürecinde, araştırma ve yayın etiğine uyuldu.

\section{BULGULAR}

Araştırmaya katılan hemşirelerin $(\mathrm{n}=158)$ yaş ortalaması $32,38 \pm 7,36$ olup çoğunluğu $(\% 44,3) \quad 19-30$ yaş aralığındadır. Hemşirelerin \%77,2'si kadın, \%72,2'si fakülte/yüksekokul mezunu, \%63,3’ü evlidir. Hemşirelerin çalışma yaşamlarına ait özellikleri incelendiğinde; \%39,2'sinin çalışma hayatlarının ilk 5 yılında oldukları, yarısının $(\% 50,6)$ dahili kliniklerde çalışmakta oldukları ve çoğunluğunun $(\% 74,7)$ nöbet tuttukları belirlendi (Tablo 1).

Tablo 1. Hemşirelerin Sosyo-demografik Özellikleri $(\mathrm{n}=158)$

\begin{tabular}{|c|c|c|c|}
\hline \multicolumn{2}{|c|}{ DEĞİŞKENLER } & Sayı & Yüzde \\
\hline \multirow[t]{4}{*}{ Yaş } & Ort:32,38 SS: 7,36 & Min:19 & Mak:53 \\
\hline & 19-30 Yaş & 70 & 44,3 \\
\hline & 31-42 Yaş & 69 & 43,7 \\
\hline & 43-53 Yaş & 19 & 12,0 \\
\hline \multirow[t]{2}{*}{ Cinsiyet } & Kadın & 122 & 77,2 \\
\hline & Erkek & 36 & 22,8 \\
\hline \multirow{4}{*}{$\begin{array}{l}\text { Eğitim } \\
\text { Durumu }\end{array}$} & Sağlık Meslek Lisesi & 16 & 10,1 \\
\hline & Meslek Yüksekokulu & 22 & 13,9 \\
\hline & Fakülte/Yüksekokul & 114 & 72,2 \\
\hline & Lisans Üstü & 6 & 3,8 \\
\hline \multirow{2}{*}{$\begin{array}{l}\text { Medeni } \\
\text { Durum }\end{array}$} & Evli & 100 & 63,3 \\
\hline & Bekar & 58 & 36,7 \\
\hline \multirow[t]{3}{*}{ Çalışma Yılı } & $1-5$ yil & 62 & 39,2 \\
\hline & 6-15 y1l & 58 & 36,7 \\
\hline & $16-29$ y1l & 38 & 24,1 \\
\hline \multirow{3}{*}{$\begin{array}{l}\text { Çalışılan } \\
\text { Birim }\end{array}$} & Dahili Klinikler & 80 & 50,7 \\
\hline & Cerrahi Klinikler & 64 & 40,6 \\
\hline & İdare ve Poliklinikler & 14 & 8,7 \\
\hline \multirow{2}{*}{$\begin{array}{l}\text { Nöbet Tutma } \\
\text { Durumu }\end{array}$} & Nöbet Tutanlar & 118 & 74,7 \\
\hline & Nöbet Tutmayanlar & 40 & 25,3 \\
\hline
\end{tabular}

Min: minimum; Mak: maksimum; Ort: ortalama; SS: standart sapma
BİFÖ ile yapılan araştırmalarda iki çeşit hesaplama yapılmaktadır. $\mathrm{Bu}$ araştırmada birinci hesaplama yöntemine göre; hemşirelerin BİFÖ puan ortalamas1 $63,98 \pm 12,41$ olup, hemşireler ölçekten en düşük 20, en yüksek 88 puan aldı (BİFÖ puan aralığı 15-90'dır). İkinci hesaplama yöntemine göre; hemşirelerin BİFÖ puan ortalaması 4,26 $\pm 1,39$ olarak hesapland1.

Tablo 2'de hemşirelerin sosyo-demografik özelliklerine göre BİÖ puan ortalamalarının dağılımı verildi. Hemşirelerin; çalışma yılları, medeni durumları, yaş grupları, eğitim durumları ve çalıştıkları birime göre BIFÖ puan ortalamaları arasında istatistiksel olarak anlamlı fark saptanmadı $(\mathrm{p}>0,05)$. Hemşirelerin cinsiyetleri ve nöbet tutma durumları ile BIFÖ ortalamaları karşılaştırıldığında; kadınların ve nöbet tutmayanların BİFÖ puan ortalamaları, erkeklere ve nöbet tutanlara göre düşüktü. $\mathrm{Bu}$ farklılık istatistiksel olarak anlamlıdır $(\mathrm{p}<0,05)$.

\section{TARTIŞMA}

Hemşirelerin bilinçli farkındalık düzeylerinin belirlendiği bu araştırmada, katılımcıların BİFÖ puan ortalamalarının orta düzeyde olduğu tespit edildi. Ülkemizde hemşirelerin bilinçli farkındalık düzeylerini ölçen, Gezer ve Özaydın'ın (16) kuşaklar arasındaki farklılığın hemşirelerin bilinçli farkındalık düzeyleri üzerine etkisi konulu çalışmasında; hemşirelerin BİFÖ puan ortalamaları $(46,07 \pm 12,77)$, bu araştırmadan farklı olarak düşük bulundu. Gezer ve Özaydın'ın çalışmasında; (16) hemşirelerin BİFÖ puan ortalamaları bu araştırma bulgularına göre düşük olmakla birlikte, çalışma yoğun bakım ve cerrahi kliniklerinde çalışan hemşireler ile gerçekleştirilmiştir. $\mathrm{Bu}$ araştırmada ise farklı olarak idari birimler ve dahili birimlerdeki hemşireler de araştırma kapsamına alınmıștır. Aradaki bu farklılık BİFÖ puan ortalamalarının farklılığına sebep olmuş olabilir. Lan ve ark. (19) kritik bakım ünitelerinde çalışan hemşirelerle yaptıkları araştırmada, BİFÖ puan ortalamasını 4,08 \pm 0,55 olarak tespit etmiştir. Sonuçlar bu araştırmanın sonuçları ile yakındır.

Horner ve ark. (12) hemşirelerde 10 haftalık bilinçli farkındalık eğitim programının etkisini değerlendirdikleri bir araştırmada; müdahale öncesi girişim grubunun BİFÖ puan ortalamaları 4,20 kontrol grubunun ise 4,70 olarak saptamıştır. Müdahale sonrası ise kontrol grubunun puan ortalamaları aynı kalırken, girişim grubunun puan ortalamaları 4,40'a yükselmiştir. Bu yükselme ile birlikte tükenmişlik ve stres puanlarının düştüğü görülmüştür. Gauthier ve ark. (13) ise hemşirelerin BİFÖ puan ortalamalarını 3,72 $\pm 0,82$ hesaplamış ve hemşirelere 30 günlük mindfulness temelli stres azaltma programı uygulamıştır. $\mathrm{Bu}$ uygulamadan sonra hemşirelerin, bilinçli farkındalık puan ortalamaları yükselmiştir. Aynı çalışmada, bilinçli farkındalık puanları yükselirken, stres ve duygusal yorgunluk puanlarının düştüğü tespit edilmiştir. $\mathrm{Bu}$ araştırmada elde edilen bilinçli farkındalık ölçek puan ortalamasına göre hemşirelerin bilinçli farkındalık düzeyleri literatür ile uyumlu bulunmuştur. Horner ve ark. (12) ve Gauthier ve ark. (13) çalışmalarında, bu araştırmaya benzer bilinçli farkındalık düzeyleri tespit edilmiştir. 
Tablo 2. Hemșirelerin Sosyo-demografik Özelliklerine Göre BİFÖ Puan Ortalamalarının Dağılımı (n=158)

\begin{tabular}{|c|c|c|c|c|c|}
\hline \multirow[t]{2}{*}{ DEĞISŞKENLER } & \multirow[b]{2}{*}{ Sayı } & \multicolumn{2}{|c|}{ BIFÖ* } & & \\
\hline & & 1. Hesaplama & 2. Hesaplama & \multicolumn{2}{|c|}{ İstatistik Değer } \\
\hline $\begin{array}{l}\text { Çalışma Yılı (Ort. } \pm \text { SS) } \\
\text { 1-5 Yil } \\
\text { 6-15 Yil } \\
\text { 16-29 Yil }\end{array}$ & $\begin{array}{l}62 \\
58 \\
38\end{array}$ & $\begin{array}{l}66,10 \pm 12,59 \\
62,60 \pm 12,73 \\
62,63 \pm 11,43\end{array}$ & $\begin{array}{l}4,40 \pm 0,83 \\
4,17 \pm 0,84 \\
4,17 \pm 0,76\end{array}$ & $1,490^{* * *}$ & 0,229 \\
\hline $\begin{array}{l}\text { Cinsiyet (Ort. } \pm \text { SS) } \\
\text { Kadın } \\
\text { Erkek }\end{array}$ & $\begin{array}{c}122 \\
36\end{array}$ & $\begin{array}{l}62,67 \pm 12,58 \\
68,42 \pm 10,89\end{array}$ & $\begin{array}{l}4,17 \pm 0,83 \\
4,56 \pm 0,72\end{array}$ & $-2,479^{* *}$ & $\mathbf{0 , 0 1 4}$ \\
\hline $\begin{array}{l}\text { Medeni Durum (Ort. } \pm \text { SS) } \\
\text { Evli } \\
\text { Bekar }\end{array}$ & $\begin{array}{c}100 \\
58\end{array}$ & $\begin{array}{l}63,69 \pm 11,58 \\
64,48 \pm 13,82\end{array}$ & $\begin{array}{l}4,24 \pm 0,77 \\
4,29 \pm 0,92\end{array}$ & $-0,386^{* *}$ & 0,700 \\
\hline $\begin{array}{l}\text { Nöbet Tutma Durumu } \\
\text { (Ort. } \pm \text { SS) } \\
\text { Tutuyor } \\
\text { Tutmuyor }\end{array}$ & $\begin{array}{c}118 \\
40\end{array}$ & $\begin{array}{l}65,98 \pm 11,02 \\
58,07 \pm 14,42\end{array}$ & $\begin{array}{l}4,39 \pm 0,73 \\
3,87 \pm 0,96\end{array}$ & $3,612^{* *}$ & $<0,001$ \\
\hline $\begin{array}{l}\text { Yaş Grupları (Ort. } \pm \text { SS) } \\
\text { 19-30 Yaş } \\
\text { 31-42 Yaş } \\
\text { 43-53 Yaş }\end{array}$ & $\begin{array}{l}70 \\
69 \\
19\end{array}$ & $\begin{array}{l}65,35 \pm 12,39 \\
63,30 \pm 12,61 \\
61,36 \pm 11,75\end{array}$ & $\begin{array}{l}4,35 \pm 0,82 \\
4,22 \pm 0,84 \\
4,09 \pm 0,78\end{array}$ & $0,952^{* * *}$ & 0,388 \\
\hline $\begin{array}{l}\text { Eğitim Durumu (Ortanca } \\
\text { (min-mak)) } \\
\text { Sağlik Meslek Lisesi } \\
\text { Meslek Yüksekokulu } \\
\text { Fakülte/Yüksekokul } \\
\text { Lisans Üstü }\end{array}$ & $\begin{array}{c}16 \\
22 \\
114 \\
6\end{array}$ & $\begin{array}{l}69,00(46-83) \\
65,00(46-86) \\
65,00(20-88) \\
64,50(49-78)\end{array}$ & $\begin{array}{l}4,60 \pm 0,80 \\
4,33 \pm 0,78 \\
4,33 \pm 0,85 \\
4,30 \pm 0,72\end{array}$ & $0,639^{* * * *}$ & 0,887 \\
\hline $\begin{array}{l}\text { Çalışılan Birim (Ortanca } \\
\text { (min-mak)) } \\
\text { Dahili Klinikler } \\
\text { Cerrahi Klinikler } \\
\text { İdare ve Poliklinikler }\end{array}$ & $\begin{array}{l}80 \\
64 \\
14\end{array}$ & $\begin{array}{l}67,50(36-87) \\
62,00(28-88) \\
59,50(20-72)\end{array}$ & $\begin{array}{l}4,50 \pm 0,71 \\
4,13 \pm 0,89 \\
3,96 \pm 0,98\end{array}$ & $5,561^{* * * * *}$ & 0,062 \\
\hline
\end{tabular}

BİFÖ: Bilinçli Farkındalık Ölçeği

Ort.: ortalama; SS: standart sapma; min.: minimum; mak.:maksimum

* Ölçeğin ortalaması ve ölçek maddelerinin ağırlıkları üzerinden hesaplanan ortalaması

**İki ortalama arasındaki farkın önemlilik testi (t testi)

***Tek yönlü varyans analizi $(\mathrm{F})$

*****Kruskal Wallis

Araştırmacıların bu bulgulardan sonra hemşirelere, onların bilinçli farkındalık düzeylerini arttırmak için girişimler uygulanması dikkat çekici bulunmuştur.

Hemşirelerin sosyo-demografik özelliklerine göre BİFÖ puan ortalamalarının dağılımını incelediğinde, erkek olan ve nöbet tutan hemşirelerin ölçek puan ortalamaları anlamlı düzeyde yüksek çıkmıştır. Gezer ve Özaydın'ın (16) 170 hemşire ile yaptıkları araştırmada hemşirelerin cinsiyetleri ve çalışma saatleri ile bilinçli farkındalıkları arasında anlamlı bir fark tespit edilmemiştir. Azak'ın (17) hemşirelik öğrencileri ile yaptığı bir araştırmada da cinsiyet ile bilinçli farkındalık düzeyleri arasında anlamlı bir fark bulunmamıştır. $\mathrm{Bu}$ araştırmada kullanılan BİFÖ'nün ileri psikometrik ölçümlerinin yapıldığ 1 MacKillop ve Anderson'ın (20) çalışmasında da cinsiyet ile ölçek puan ortalaması arasında herhangi bir fark saptanmamıştır. Bu araştırmada elde edilen, erkek olan ve nöbet tutan hemşirelerin bilinçli farkındalık düzeyinin yüksek olması yapılan başka araştırma bulguları ile benzer bulunmamıştır.

\section{SONUÇ}

Araştırma sonucunda; hemşirelerin bilinçli farkındalıklarının orta düzeyde olduğu ve cinsiyet ve çalışma şekline göre gruplar arasında fark olduğu tespit edildi. Araştırmanın sonuçları bir üniversite hastanesi ile sınırlıdır. Araştırmalar bilinçli farkındalık eğitiminin hemşirelerde bilinçli farkındalık düzeyini arttırdığı yönündedir $(12,13)$. Hemşirelerde bilinçli farkındalığı arttırmaya yönelik araştırmalar önerilebilir.

\section{TEŞEKKÜR}

Araştırmanın veri toplama ve veri girişi aşamalarına destekleri için, Özge Coşkun, Tuğçe Nur Söğüt, Maviye Nur Öztürk, Gülhan Taşkın ve Rahime Ekici' ye teşekkür ederiz. Ayrıca araştırmaya katılan tüm hemşirelere teşekkürlerimizi sunarız.

Yazarların Katkıları: Fikir/Kavram: E.A.; Tasarım: E.A., S.A.; Veri Toplama ve/veya İşleme: E.A.; Analiz ve/veya Yorum: E.A., S.A.; Literatür Taraması: E.A., S.A.; Makale Yazımı: E.A., S.A.; Eleştirel İnceleme: S.A. 


\section{KAYNAKLAR}

1. Kabat-Zinn J. Indra's net at work: the mainstreaming of dharma practice in society. In: Watson G, Batchelor S, editors. The psychology of awakening: Buddhism, science, and our day-to-day lives. North Beach: ME. Weiser; 2000. p. 225-49.

2. Bishop SR, Lau M, Shapiro S, Carlson L, Anderson ND, Carmody J, et al. Mindfulness: A proposed operational definition. Clinical Psychology: Science and Practice. 2006; 11(3): 230-41.

3. Atalay Z. Mindfulness: farkındalıkla anda kalabilme sanat1. 4. basım. İstanbul: İnkılap Yayınevi; 2020.

4. Kabat-Zinn J. Wherever you go there you are. 10th. ed. New York: Hyperion; 2005.

5. Brown KW, Ryan RM. The benefits of being present: Mindfulness and its role in psychological well-being. Journal of Personality and Social Psychology. 2003; 84(4): 822-48.

6. Deci EL, Ryan RM. Self-determination theory: When mind mediates behaviour. The Journal of Mind and Behavior. 1980; 1(1): 33-43.

7. Morone NE, Greco CM, Weiner DK. Mindfulness meditation for the treatment chronic low back pain in older adults: A randomized controlled pilot study. Pain. 2008; 134(3): 310-9.

8. Grant JA, Rainville P. Pain sensitivity and analgesic effects of mindful states in Zen meditators. A crosssectional study. Psychosomatic Medicine. 2009; 71(1): 106-14.

9. Ivanowski B, Malhi GS. The psychological and neuropsychological concomitants of mindfulness forms of meditation. Acta Neuropsychiatrica. 2007; 19(2): 76-91.

10. Shapiro SL, Oman D, Thorsen CE, Plante TG, Flinders T. Cultivating mindfulness: Effects on wellbeing. Journal of Clinical Psychology. 2008; 65(7): 840-62.

11. Sanko J, MacKay M, Rogers S. Exploring the impact of mindfulness meditation training in pre-licensure and post graduate nurses. Nurse Education Today. 2016; 45: 142-7.

12. Horner JK, Piercy BS, Eure L, Woodard EK. A pilot study to evaluate mindfulness as a strategy to improve inpatient nurse and patient experiences. Applied Nursing Research. 2014; 27(3): 198-201.

13. Gauthier T, Meyer RML, Grefe D, Gold JI. An onthe-job mindfulness-based intervention for pediatric ICU nurses: A pilot. Journal of Pediatric Nursing. 2015; 30(2): 402-9.

14. Karaca A, Şişman N. Effects of a stress management training program with mindfulness-based stress reduction. The Journal of Nursing Education. 2019; 58(5): 273-80.

15. Spinelli C, Wisener M, Khoury B. Mindfulness training for health care professionals and trainees: A meta-analysis of randomized controlled trials. Journal of Psychosomatic Research. 2019; 120(5): 29-38.

16. Özaydın E. Kuşaklar arasındaki farklılığın hemşirelerin bilinçli farkındalık düzeyleri üzerine etkisi [Uzmanlık tezi]. Aydın: Adnan Menderes Üniversitesi, Sağlık Bilimleri Enstitüsü; 2019.

17. Azak A. Hemşirelik öğrencilerinin bilinçli farkındalık düzeylerinin belirlenmesi. Hemşirelikte Eğitim ve Araştırma Dergisi. 2018; 15(3): 170-6.

18. Özyeşil Z, Arslan Ç, Kesici Ş, Deniz ME. Bilinçli farkındalık ölçeğini Türkçeye uyarlama çalışması. Eğitim ve Bilim Dergisi. 2011; 36(160): 224-35.

19. Lan HK, Subramanian P, Rahmat N, Kar PC. The effects of mindfulness training program on reducing stress and promoting wellbeing among nurses in critical care units. Australian Journal of Advanced Nursing. 2014; 31(3): 22-31.

20. MacKillop J, Anderson EJ. Further psychometric validation of the mindful attention awareness scale (MAAS). Journal of Psychopathology and Behavioral Assessment. 2007; 29(1): 289-93. 